\title{
Mechanisms utilized by feline adipose- derived mesenchymal stem cells to inhibit T lymphocyte proliferation
}

\author{
Nopmanee Taechangam ${ }^{1,3}$, Smita S. Iyer ${ }^{1}$, Naomi J. Walker ${ }^{1,3}$, Boaz Arzi ${ }^{2,3}$ and Dori L. Borjesson ${ }^{1,3^{*}}$
}

\begin{abstract}
Background: Feline adipose-derived mesenchymal stem cells (ASCs) have been successfully used in clinical trials for the treatment of immune-mediated diseases with T cell dysregulation. However, the immunomodulatory pathways utilized by feline ASCs to suppress T cell activation have not been fully determined. We investigated the mechanisms used by feline ASCs to inhibit T cell proliferation, including the soluble factors and the cell-cell contact ligands responsible for ASC-T cell interaction.

Methods: The immunomodulatory activity of feline ASCs was evaluated via cell cycle analysis and in vitro mixed leukocyte reaction using specific immunomodulatory inhibitors. Cell-cell interactions were assessed with static adhesion assays, also with inhibitors.

Results: Feline ASCs decrease T cell proliferation by causing cell cycle arrest in G0-G1. Blocking prostaglandin (PGE 2 ), but not IDO, partially restored lymphocyte proliferation. Although PDL-1 and CD137L are both expressed on activated feline ASCs, only the interaction of intercellular adhesion molecule 1 (ICAM-1, CD54) with its ligand, lymphocyte function-associated antigen 1 (LFA-1, CD11a/CD18), was responsible for ASC-T cell adhesion. Blocking this interaction reduced cell-cell adhesion and mediator (IFN- $\gamma$ ) secretion and signaling.

Conclusions: Feline ASCs utilize PGE 2 and ICAM-1/LFA-1 ligand interaction to inhibit T cell proliferation with a resultant cell cycle arrest in G0-G1. These data further elucidate the mechanisms by which feline ASCs interact with T cells, help define appropriate T cell-mediated disease targets in cats that may be amenable to ASC therapy, and may also inform potential translational models for human diseases.
\end{abstract}

Keywords: Mesenchymal stem cell, Adipose tissue, Feline, Immunomodulation, soluble mediators, ligands

\section{Background}

Mesenchymal stem cells (MSCs) are a heterogeneous, multipotent stromal cell population, capable of proliferating in vitro as plastic-adherent cells with fibroblast-like morphology and differentiating into bone, cartilage, and adipose cells [1]. Aside from their regenerative properties, MSCs also possess immunomodulatory properties and have been used extensively to treat a wide variety of immune-mediated diseases, both in human and veterinary

\footnotetext{
* Correspondence: dlborjesson@ucdavis.edu

${ }^{1}$ Department of Pathology, Microbiology and Immunology, Vet Med 3A,

University of California, 1285 Veterinary Medicine Mall, Davis, CA 95616, USA

${ }^{3}$ Veterinary Institute for Regenerative Cures, School of Veterinary Medicine,

University of California, Davis, CA 95616, USA

Full list of author information is available at the end of the article
}

medicine [2]. In veterinary medicine, adipose-derived mesenchymal stem cells (ASCs) have been successfully used to treat cats with feline chronic gingivostomatitis (FCGS), a severe debilitating oral immune-mediated disease $[3,4]$, but the mechanisms by which feline ASCs modulate the immune system have not been fully elucidated.

MSCs can be immunosuppressive and can inhibit the mitogen-induced response of naïve $\mathrm{T}$ lymphocytes [5], both $\mathrm{CD} 4+$ and $\mathrm{CD} 8+$, as well as of natural killer (NK) cells [6]. There are several possible mechanisms by which MSCs may inhibit T lymphocyte proliferation including the induction of apoptosis, cell cycle arrest, induction of a phenotype switch to regulatory $\mathrm{T}$ cells, or decreasing $\mathrm{T}$ lymphocyte activation, ultimately leading 
to anergy [7]. Suppression of $\mathrm{T}$ cell proliferation by MSCs can be mediated by secreted soluble factors because the separation of MSCs and activated T lymphocytes by a transwell can inhibit proliferation without the presence of cell-cell contact $[8,9]$. However, direct cellcell contact is also important in MSC regulation of $\mathrm{T}$ lymphocyte function in both humans and cats $[8,10]$.

MSC immunosuppressive functions require preliminary activation by immune cells through the secretion of IFN- $\gamma$, a pro-inflammatory cytokine $[6,11]$. Activated feline ASCs secrete high levels of immunomodulatory mediators, including indoleamine 2,3 dioxygenase (IDO), prostaglandin E2 (PGE $)$, interleukin (IL)-6, IL-8, and transforming growth factor beta (TGF $\beta$ ) similar to human MSCs. However, unlike human MSCs, the secretion of $\mathrm{PGE}_{2}$ and IDO by feline ASCs is significantly reduced in the absence of direct-cell contact [8]. In contrast to other species, including humans, dogs, and horses, feline ASCs inhibit lymphocyte proliferation in the context of significantly increased concentration of IFN- $\gamma[8,12,13]$.

Several cell ligand pairs have been implicated in MSC and $\mathrm{T}$ lymphocyte adhesion and signaling that subsequently impact the secretion of soluble immunomodulatory factors. These ligand pairs include ICAM-1/LFA-1, VCAM-1/VLA-4, and PDL-1/PD-1 [14, 15]. In murine MSCs, ICAM-1 is a requirement for lymphocyte-MSC adhesion and blocking ICAM-1 ligand reduced T cell accumulation around MSCs and reversed the suppression of lymphocyte proliferation [15]. ICAM-1 also plays a crucial role, particularly in $\mathrm{T}$ cell interactions with antigenpresenting cells, and is essential for the immunosuppressive effects of murine bone marrow-derived MSCs [15, 16]. PDL1 and PDL-1, a negative costimulatory molecule, has also been implicated in contact-dependent suppression in human MSCs [14, 17].

Our data from in vivo studies suggest that one mechanism by which feline ASCs decrease T cell-mediated inflammation is via the induction of CD8+ regulatory T cells [4]. Other groups have shown that CD137-CD137L costimulation can induce CD8+ regulatory $\mathrm{T}$ cells in the presence of IFN- $\gamma[8,18,19]$. Co-stimulation through the CD137-137L pathway also enhances suppressive $T$ cell function and induces activated $\mathrm{T}$ cell anergy in human immune-mediated diseases [20,21].

The purpose of this study was to define the mechanisms used by feline ASCs to suppress T lymphocyte proliferation, focusing on both soluble mediators and direct cellcell contact ligands. Similar to human ASCs, we found that (1) feline ASCs induce G0-G1 cell cycle arrest in mitogenactivated T lymphocytes, (2) $\mathrm{PGE}_{2}$ is a primary soluble factor partially responsible for the inhibition of $\mathrm{T}$ lymphocyte proliferation, and (3) a crucial ligand pair mediating feline ASC and T lymphocyte adhesion and secretion profile is ICAM-1/LFA-1. Notably, the increase in IFN- $\gamma$ secretion induced after feline ASC-T cell direct interaction is abrogated when ICAM-1 is blocked. These findings shed light on both shared and unique aspects of feline ASC biology that may underscore how the administration of ASCs results in long-term reprograming of the immune system in cats with FCGS.

\section{Materials and methods}

Feline adipose-derived mesenchymal stem cells (ASCs)

Low passage (P1-P5) adipose-derived feline mesenchymal stem cells (ASCs) were isolated from subcutaneous feline adipose tissue surgically obtained from specific pathogenfree (SPF) cats or from client-owned cats undergoing routine surgery. Fat collection was conducted according to a protocol approved by the Institutional Animal Care and Use Committee, and the Clinical Trials Review Board, UCD (protocol number 18422). All owners of clientowned cats signed an informed consent form. All cats were free of feline immune deficiency virus and feline leukemia virus infection. ASC isolation and expansion was performed at the UC Davis William R. Pritchard Veterinary Medical Teaching Hospital Regenerative Medicine Laboratory, exactly as previously described [4].

\section{ASC culture and expansion}

Feline ASCs were expanded as previously described [22]. In brief, cryopreserved ASCs were thawed in a $37^{\circ} \mathrm{C}$ water bath and seeded into tissue culture flasks with Dulbecco's modified Eagle's medium (DMEM; Corning Life Sciences), $10 \%$ fetal bovine serum (HyClone Inc.), and 1\% penicillin/ streptomycin (Thermo Fisher Scientific) and incubated at $37^{\circ} \mathrm{C}$ in $5 \% \mathrm{CO}_{2}$ at $90 \%$ humidity. Feline ASCs from passages $2-5$ were used in the experiments. All ASC lines passed quality control assays including bacterial culture (all were sterile), high viability (>90\%), positive for CD90 (identity marker), negative for CD18 (purity marker), and negative for endotoxin and Mycoplasma.

\section{Peripheral blood monocular cell (PBMC) inhibition assay-mixed leukocyte reaction (MLR)}

Feline ASCs were tested for their capability to inhibit lymphocyte proliferation with a mixed leukocyte reaction (MLR), carried out as previously described [4]. In brief, PBMCs were isolated from whole blood using gradient centrifugation and were co-incubated with irradiated ASCs in culture wells at a 1:5 (PBMC to ASC) ratio and activated with $5 \mathrm{mg} / \mathrm{mL}$ concanavalin A (ConA; Sigma-Aldrich). Cells were co-cultured for 4 days. Control wells included PBMCs alone and ConA-stimulated PBMCs. To determine indoleamine 2,3-dioxygenase (IDO) activity, the experiment was run as described; however, the media was supplemented with l-tryptophan (Sigma-Aldrich) to a final concentration of $600 \mu \mathrm{M}$. To measure proliferation, wells were spiked with 5-bromo-29-deoxyuridine (BrdU) at day 3 and 
then cells were collected and processed per manufacturer's instructions (BrdU Flow Kit; BD Biosciences) at day 4.

Some protocols included the addition of antibodies to block TGF- $\beta(10 \mu \mathrm{g} / \mathrm{mL}$, anti TGF- $\beta 1$ mouse monoclonal IgG, clone 9106, R\&D systems), or interferon gamma (IFN$\gamma, 15 \mu \mathrm{g} / \mathrm{mL}$, goat anti-feline polyclonal antibody \#AF674, R\&D systems), or chemicals to block prostaglandin E2 $\left(\mathrm{PGE}_{2}, 10 \mu \mathrm{m} / \mathrm{mL}\right.$, indomethacin, Cayman Chemical), or IDO $(500 \mu \mathrm{M} / \mathrm{mL}$ 1-methyl-L-tryptophan (Sigma-Aldrich), a competitive inhibitor of tryptophan). Inhibitor concentration was determined by titration studies in our laboratory or based on previous publications [23].

\section{Feline ASCs and PBMC phenotyping}

For the analysis of surface expression on feline ASCs and PBMCs, cells were harvested and resuspended at a concentration of $1 \times 10^{6} \mathrm{cell} / \mathrm{mL}$ in flow buffer (DPBS, $1 \%$ normal equine serum, $10 \mathrm{mM}$ EDTA, and $0.1 \%$ sodium azide). Cells were incubated with antibodies for $30 \mathrm{~min}$ at room temperature. Antibodies included mouse anti-feline CD4PE (clone 3-4F4, Southern Biotech), mouse anti-feline CD5-FITC (clone f43, Southern Biotech), mouse anti-feline CD8 $\alpha$-PE (clone Fe1.10E9, Leukocyte Antigen Biology Laboratory, UC Davis), mouse anti-human I-CAM 1 (CD54, clone MEM-111, Thermo Fisher Scientific), rat anti-mouse CD137L (clone TKS-1, Bio X Cell), polyclonal goat antihuman-PD-1 (cat\#AF1086, R\&D systems), polyclonal goat anti-human-PDL-1/B7-H1 (cat\#AF156, R\&D systems). The secondary antibody used for indirect labeling was RPhycoerythrin $\mathrm{F}\left(\mathrm{ab}^{\prime}\right)_{2}$ Fragment donkey anti-goat IgG (Jackson ImmunoResearch Inc.) and Fluorescein Rabbit Anti-Rat IgG (Vector Laboratories). Cells were analyzed with a Beckman-Coulter Cytomics FC500 flow cytometer. Data analyses were done on Flowjo flow cytometry software (Tree Star, Inc.).

\section{Cell cycle analysis}

Lymphocyte DNA content was determined with 7-aminoactinomycin D (7-AAD; BD Biosciences) incorporation to distinguish between lymphocyte populations in the $\mathrm{S}$ phase, G1 phase, and G2-M phase in conjunction with BrdU incorporation (FITC BrdU Flow Kit; BD Biosciences). PBMCs were collected for 4 consecutive days from coincubation experiments with feline ASCs. Cells were analyzed with a Beckman-Coulter Cytomics FC500 flow cytometer. Data analyses were done on Flowjo flow cytometry software (Tree Star, Inc.).

\section{Detection of intracellular IFN- $\gamma$}

PBMCs were collected from the MLR on day 4 and resuspended in RPMI 1640 media with 10\% heat-inactivated FBS, $1 \%$ Gluta-Max, $1 \mathrm{mM}$ sodium pyruvate, $1 \%$ penicillin-streptomycin, $2 \mathrm{mM}$ HEPES, 0.1\% MEM NEAA, and $55 \mu \mathrm{M} \quad \beta$-mercaptoethanol. Collected cells were stimulated with $25 \mathrm{ng} / \mathrm{mL}$ Phorbol-12-Myristate-13-Acetate (PMA, Sigma-Aldrich) and $500 \mathrm{ng} / \mathrm{mL}$ ionomycin (Sigma-Aldrich), treated with $1 \mu \mathrm{g} / \mathrm{mL}$ Brefeldin A and incubated for $3 \mathrm{~h}$ at $37^{\circ} \mathrm{C}$. Cells were then washed, stained with a viability dye (Fixable Viability Dye eFlour ${ }^{\circ} 780$, eBioscience), fixed with $2 \%$ paraformaldehyde, permeabilized in wash buffer (DPBS with $0.5 \%$ bovine serum albumin, $0.1 \%$ saponin, and $0.02 \%$ sodium azide), and stained with anti-bovine IFN- $\gamma$-AlexaFluor647 antibody (clone CC302, Bio-Rad). Cells were analyzed with Beckman-Coulter Cytomics FC500 flow cytometer. Data analyses were done on Flowjo flow cytometry software (Tree Star, Inc.).

\section{Detection of secreted mediators}

IDO, nitric oxide (NO), $\mathrm{PGE}_{2}$, and IFN- $\gamma$ were measured in the MLR culture supernatant collected on day 4. Supernatants were stored at $-80^{\circ} \mathrm{C}$ until analyzed. $\mathrm{PGE}_{2}$ and IFN $-\gamma$ concentration were measured using commercially available feline-specific ELISA kits (Enzo Life Sciences and $R \& D$ systems, respectively), according to the manufacturer's instructions [8]. IDO activity was determined through the measurement of colorimetric kynurenine level assay, and $\mathrm{NO}$ was measured with a Griess reagent system (Griess Reagent System, Promega Corporation), both performed exactly as previously described [12]. All samples were read on a Synergy HT Multi-Mode microplate reader with Gen5 software (Biotek).

\section{MSC-PBMC static adhesion assay}

Static adhesion assay was modified from Ren et al. [15]. In brief, feline ASCs were plated in 24 -well plates $\left(5 \times 10^{4}\right.$ cells/well) in $750 \mu \mathrm{L}$ standard culture medium. Isolated PBMCs were fluorescently labeled with CellTracker ${ }^{\mathrm{Tm}}$ Green CMFDA (5-chloromethylfluorescein diacetate, Thermo Fisher Scientific) and activated with $5 \mu \mathrm{g}$ ConA for $1 \mathrm{~h}$ prior to adding to the ASCs $\left(1 \times 10^{6}\right.$ cells/well $)$. Cells were permitted to adhere to ASCs for $2 \mathrm{~h}$ at $37^{\circ} \mathrm{C}$ in $5 \% \mathrm{CO}_{2}$. The plates were then rotated at $300 \mathrm{rpm}$ for 5 min and washed with DPBS twice to remove non-attached PBMCs. Fluorescence was detected using a Synergy HT Multi-Mode microplate reader at $485-\mathrm{nm}$ wavelength prior to and after washing to quantify the change in fluorescent intensity. The plate was also visualized and photographed on an inverted fluorescent microscope (EVOS FL, Thermo Fisher Scientific). In some experiments, blocking antibodies to ICAM 1 (anti-human CD54, clone MEM-111, Thermo Fisher Scientific), LFA-1 (anti-human clone R7.1, eBioscience), CD137 (anti-mouse clone 17B5, Bio X Cell), CD137L (anti-mouse clone TKS-1, Bio X Cell), PD-1 (anti-human PD-1, polyclonal goat IgG, R\&D systems), or PDL-1 (anti-human PDL-1, polyclonal goat IgG, R\&D systems) were added to determine which ligands mediated PBMC-ASC adhesion. The concentration 
of antibodies used was determined by titration studies in our laboratory.

\section{Statistical analyses}

Data analysis was performed using GraphPad Prism version 7 software (GraphPad Software). All experiments were performed with $n=5$ (feline ASC lines and PBMCs donors) unless otherwise indicated. Statistical significance between two groups was determined by non-parametric Mann-Whitney-Wilcoxon test due to small sample size. $p$ values $<0.05$ were considered statistically significant.

\section{Results}

\section{Activated feline CD4+ and CD8+ T lymphocytes both secrete IFN- $\gamma$}

Feline ASCs decrease activated $\mathrm{T}$ cell proliferation and secretion of pro-inflammatory cytokines, notably tumor necrosis factor alpha (TNF- $\alpha$ ). However, unlike other species, including people, dogs, and horses, feline ASCs inhibit lymphocyte proliferation in the presence of increased IFN$\gamma$ concentration when ASCs are in direct contact with lymphocytes $[6,8,12,13,24]$. We previously hypothesized that feline ASCs could be licensed by IFN- $\gamma$ and this signaling may be critical for the long-term reprograming of CD8+ regulatory T lymphocytes [25-27]. Our previous work did not identify the cell types responsible for IFN- $\gamma$ secretion in our assays. As ASCs inhibit lymphocyte proliferation regardless of cell-cell contact, high IFN- $\gamma$ concentration can be used as a surrogate marker of contact-mediated $\mathrm{T}$ cell inhibition and the reduction of IFN- $\gamma$ secretion can be used as a marker of effective blockade of this pathway.

We found that feline CD4 and CD8 T lymphocytes both secrete IFN- $\gamma$ after mitogen activation (Fig. 1a-d) and the secretion of IFN- $\gamma$ from CD4+ T lymphocytes is significantly increased upon co-incubation with feline ASCs $(p=0.02$; Fig. 1g), and the level of IFN- $\gamma$ is sustained with a tendency to increase in CD8+ T lymphocytes in the presence of feline ASCs (Fig. 1h).

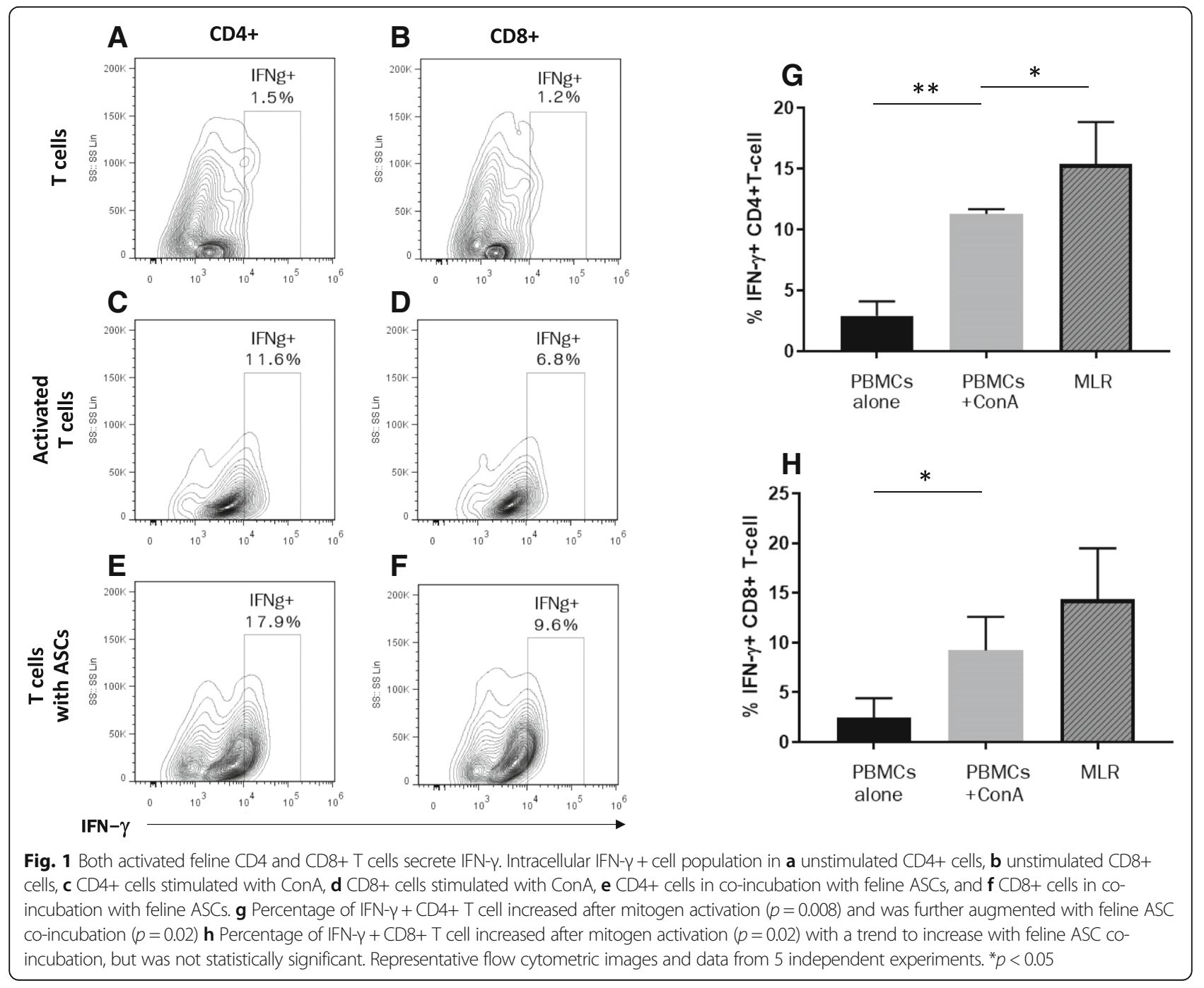


Feline ASCs decrease activated PBMC viability and inhibit lymphocyte proliferation through the induction of G0-G1 cell cycle arrest

Feline ASCs inhibit mitogen-activated $\mathrm{T}$ cell proliferation with and without the presence of cell-to-cell contact [8], but the mechanism of action is not known. Here we demonstrate that feline PBMC viability decreased upon mitogen activation $(p=0.04)$ and was even further exacerbated by the co-incubation with feline ASCs $(p=0.008$; Fig. 2ad). Additionally, cell cycle analysis revealed that the percentage of $\mathrm{T}$ lymphocytes in the G0-G1 phase increased with a concurrent decrease in the S-phase upon coincubation with feline ASCs $(p=0.03)$. However, feline ASCs did not undergo increased apoptosis compared to the mitogen-activated condition (Fig. 2d-f). These findings suggest that feline ASCs inhibit activated PBMC viability and inhibit the proliferation of mitogen-activated $\mathrm{T}$ lymphocytes through the induction of G0-G1 cell cycle arrest.

\section{Feline ASC secretion of $\mathrm{PGE}_{2}$ is partially responsible for} inhibiting lymphocyte proliferation

Our previous data suggested that there are at least 2 mechanisms by which feline ASCs inhibit activated $\mathrm{T}$ cell proliferation, one relying on direct contact between the ASCs and T lymphocytes and another dependent on soluble factors [3, 8]. Feline ASCs constitutively produce low concentrations of immunomodulatory mediators in the absence of activation, but secretion is much higher in the presence of mitogen-activated $\mathrm{T}$ cells, particularly the secretion of IDO and $\mathrm{PGE}_{2}$ which is enhanced by direct cell contact [8]. Although the feline ASC secretion profile has largely been determined [8], we wanted to (1) more fully elucidate mediators secreted by feline ASCs (in the presence and absence of contact) and (2) identify the soluble mediators critical for the inhibition lymphocyte proliferation, focused on TGF- $\beta$, IFN- $\gamma$, $\mathrm{PGE}_{2}$, and IDO.

Nitric oxide (NO) may play an important role in human MSC-induced T lymphocyte immunosuppression [28]; however, feline ASCs did not secrete substantial quantities of $\mathrm{NO}$ even in the presence of activated $\mathrm{T}$ lymphocytes (Fig. 3a). Like PGE 2 , IDO was secreted by activated feline ASCs and PBMCs [8] but only in the presence of direct cell-contact ( $p=0.008$; Fig. 3b).

We found that $\mathrm{PGE}_{2}$ was partially responsible for the inhibition of activated lymphocytes by feline ASCs $(p=$ $0.03)$; however, blocking TGF- $\beta$, IFN- $\gamma$, and IDO did not significantly restore lymphocyte proliferation (Fig. 3c-e). Blocking both $\mathrm{PGE}_{2}$ and IDO demonstrated a slight increase, but did not significantly restore lymphocyte proliferation (Fig. 3e).

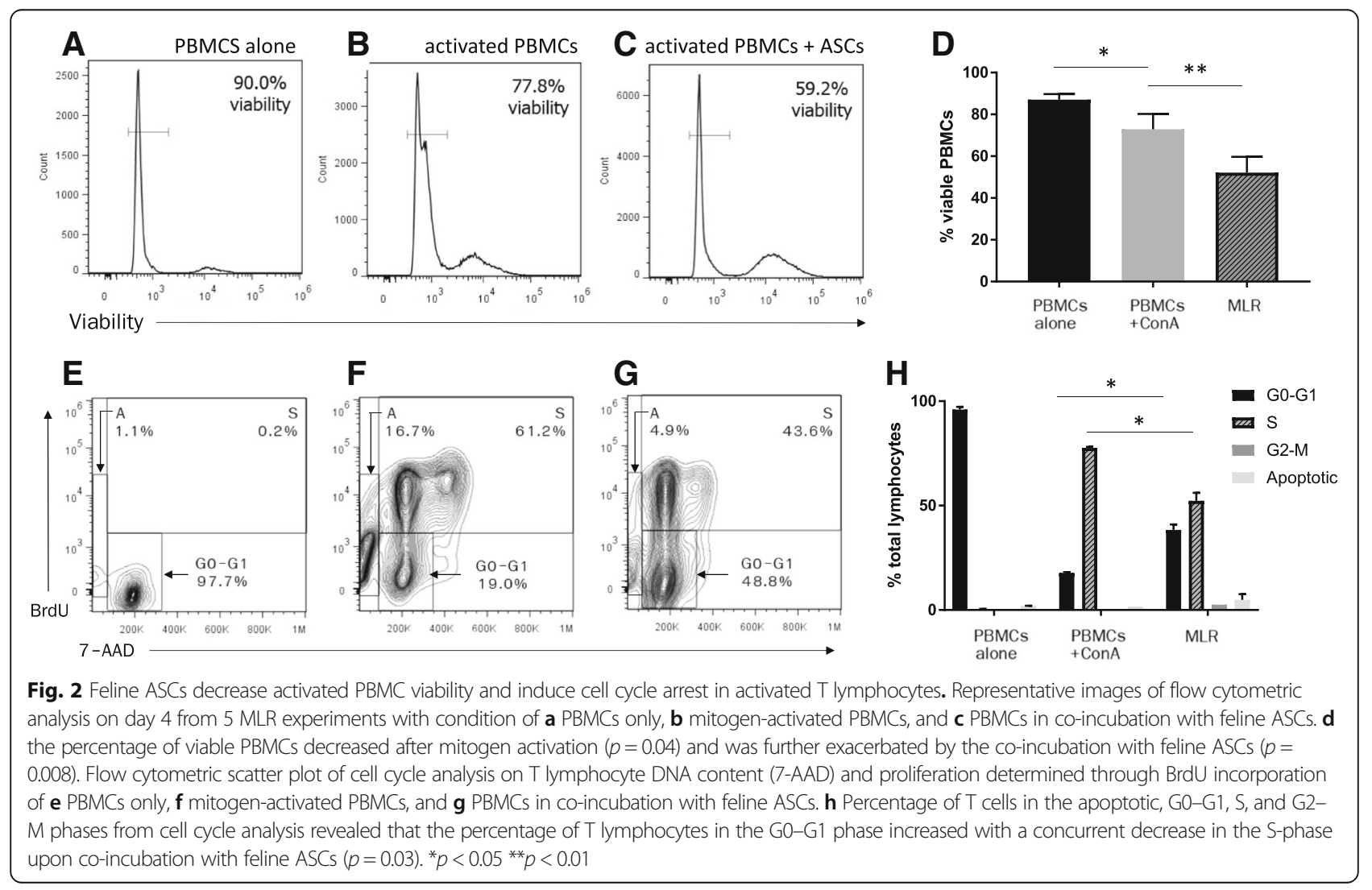




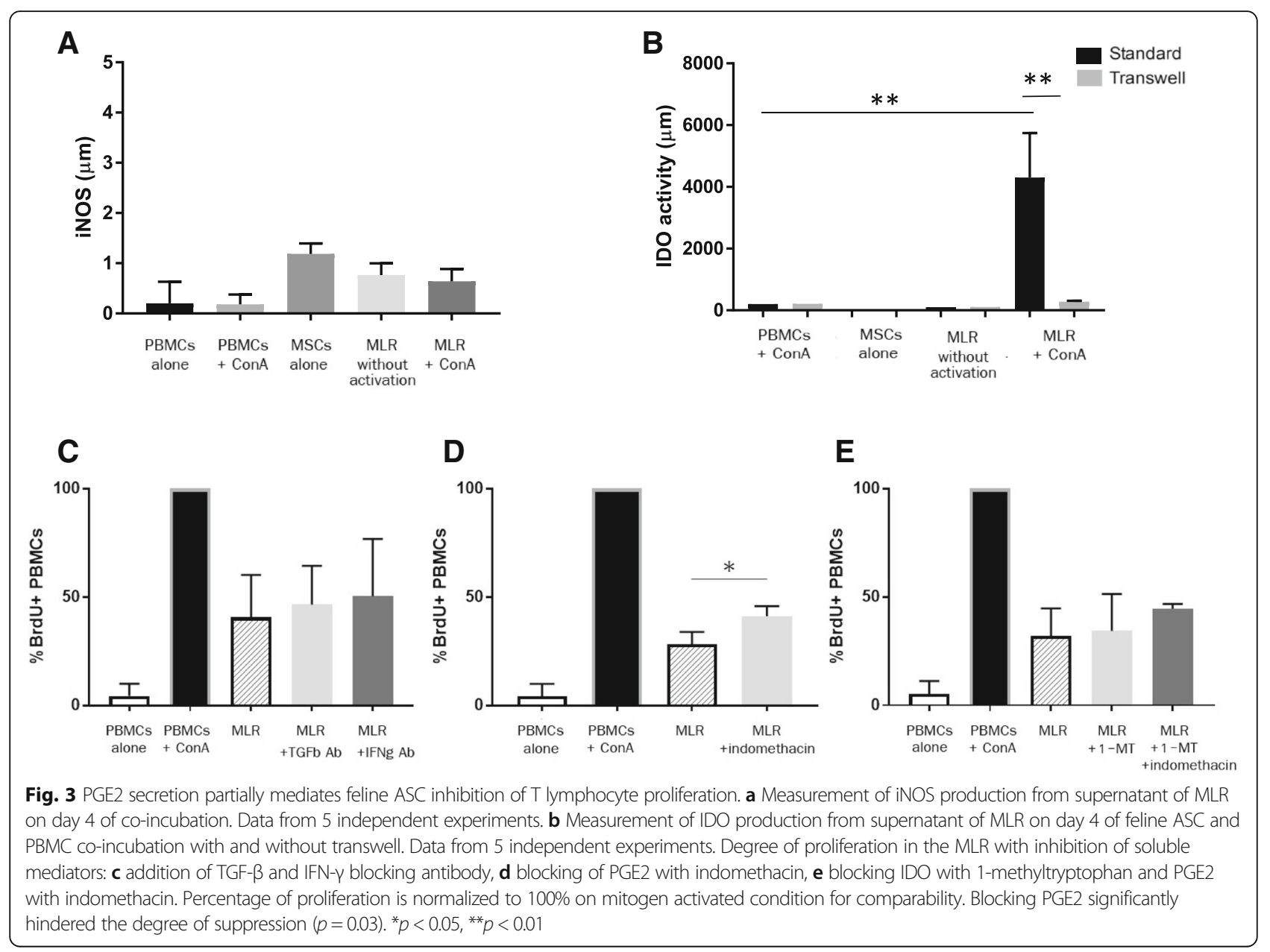

ICAM-1 mediates the adhesion between feline ASCs and T lymphocytes

Cell-cell contact is an important factor for MSC-mediated $\mathrm{T}$ cell immunosuppression [12, 17, 29]. Given the importance of cell-cell contact and the unique contact-dependent mediator secretion profile for feline ASCs in particular, we investigated the potential role of 3 ASC cell surface receptors [CD54 ICAM-1, PDL-1, and CD137L] to regulate T cell-feline ASC adhesion. We first determined if ICAM-1, PDL-1, and CD137L were expressed on feline MSCs and whether co-incubation of activated T cells with MSCs resulted in increased expression of these surface receptors. Flow cytometric analysis revealed that activated feline ASCs expressed ICAM-1, CD137L, and PDL-1 on their surface (Fig. $4 \mathrm{a}-\mathrm{c}$ ). Activated feline T cells express LFA-1 [30], PD-1 [31], and CD137 [unpublished data]; however, it was unknown if, similar to human MSCs, ASC coincubation with activated $\mathrm{T}$ cells would decrease PD-1, CD137, and LFA-1 expression on activated T cells. We found that, unlike human MSCs, feline ASCs did not decrease PD-1 expression on activated T cells (Additional file 1).
We then utilized blocking antibodies against ICAM-1/ LFA-1, CD137/CD137L, and PD-1/PDL-1 to directly test whether these ligand pairs mediated feline ASClymphocyte adhesion in static conditions. Neither the blockade of CD137/CD137L nor PD-1/PDL-1 significantly altered T cell-ASC adhesion (Fig. 4d-j). However, blocking ICAM-1 significantly reduced $\mathrm{T}$ cell-ASC adhesion to levels comparable to adhesion between non-activated $\mathrm{T}$ cells and ASCs $(p=0.045$; Fig. 5a-d). Blocking ICAM-1 also resulted in a concurrent significant reduction of IFN- $\gamma$ secretion $(p=0.002$; Fig. 5e). These findings collectively suggest that ICAM-1 is important for mediating the adhesion between feline ASCs and T cell and may be involved in contact-dependent immunomodulation by feline ASCs.

\section{Discussion}

Cats are increasingly used as translational models for MSC-based therapies, and a number of inflammatory feline diseases resemble human inflammatory conditions $[32,33]$. Feline ASCs have been used in a number of clinical trials for diseases including feline chronic gingivostomatitis (FCGS), chronic enteropathy, chronic kidney 


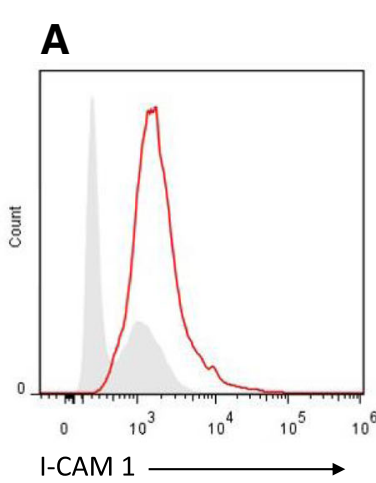

B

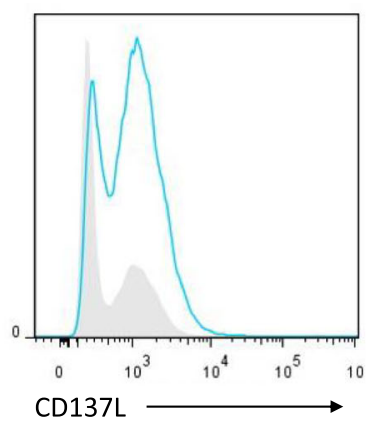

C

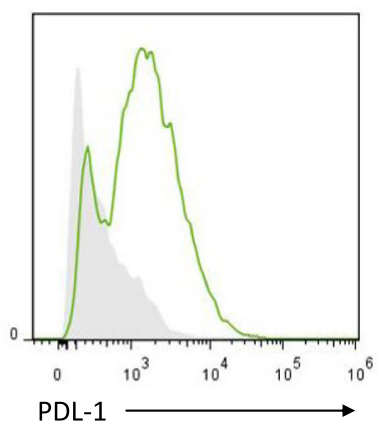

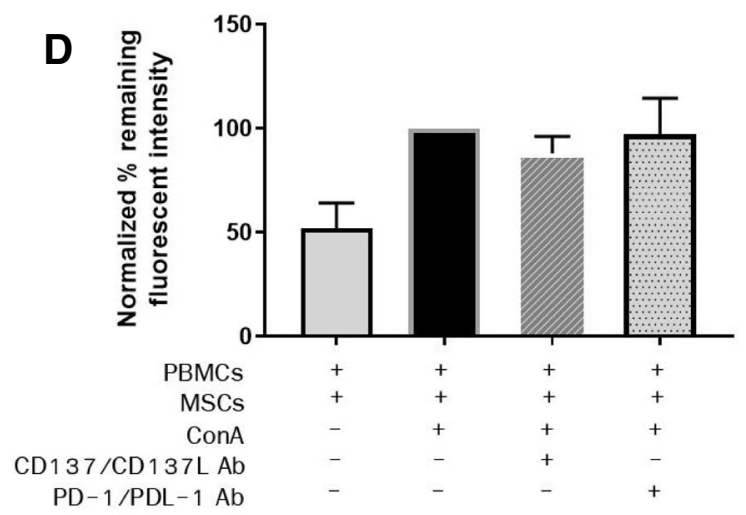

CD137-CD137L
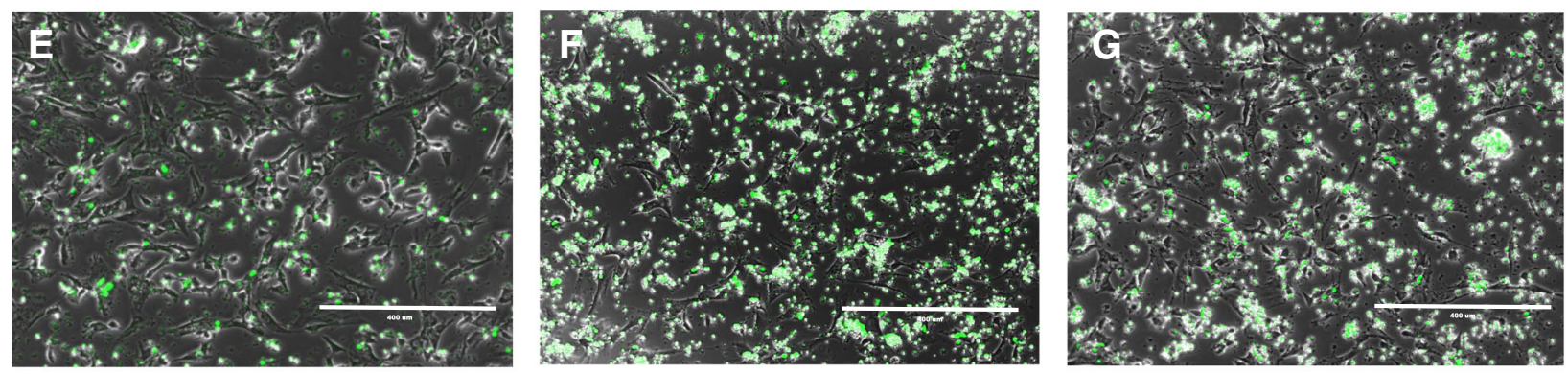

PD-1/PDL-1
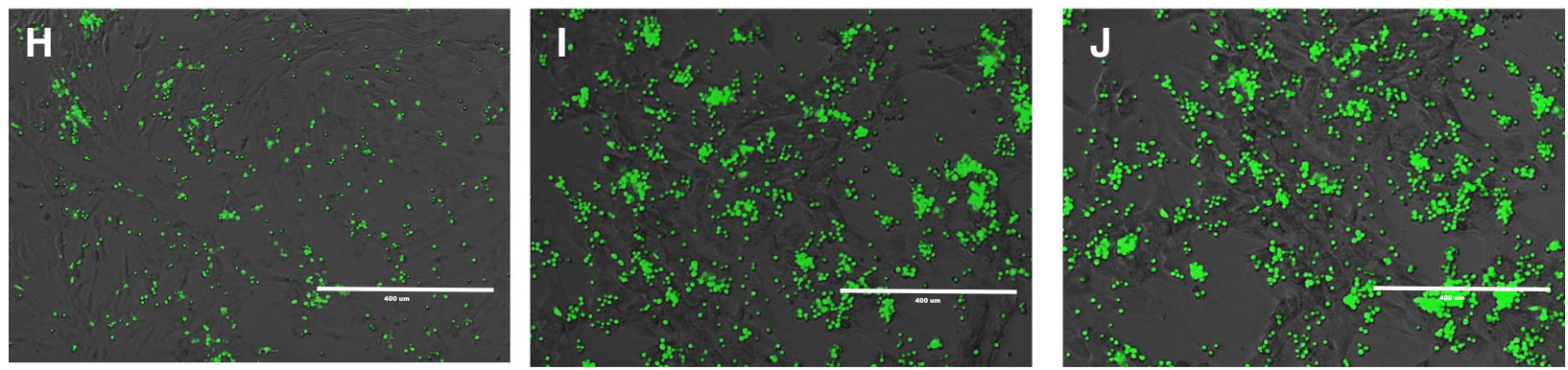

Fig. 4 ICAM-1, CD137L, and PDL-1 are all expressed on activated feline ASCs; however, CD137L and PDL-1 do not mediate MSC-T cell adhesion. Expression of a ICAM-1, b CD137L, and c PDL-1 ligands on activated feline ASCs. Gray histogram indicated background fluorescence of unstained samples. d Percentage of remaining fluorescence intensity from CMFDA-labeled PBMCs after removal of non-adherent cells from static adhesion assay after the addition of CD137/CD137L and PD-1/PDL-1 blocking antibodies. Data is normalized to 100\% on a standard MLR condition for comparability. Fluorescent images of static adhesion assay demonstrating adherent lymphocytes to ASCs from $\mathbf{e}, \mathbf{h}$ non-activated MLR, $\mathbf{f}, \mathbf{i}$ stimulated MLR with ConA, and $\mathbf{g}$, j stimulated MLR with ConA and addition of CD137/CD137L and PD-1/PDL-1 blocking antibodies respectively. Scale bar $=400 \mu \mathrm{m}$. Representative flow analysis images in $\mathbf{a}-\mathbf{c}$ from 3 independent experiments. Data gathered in $\mathbf{d}$ from 5 independent experiments 

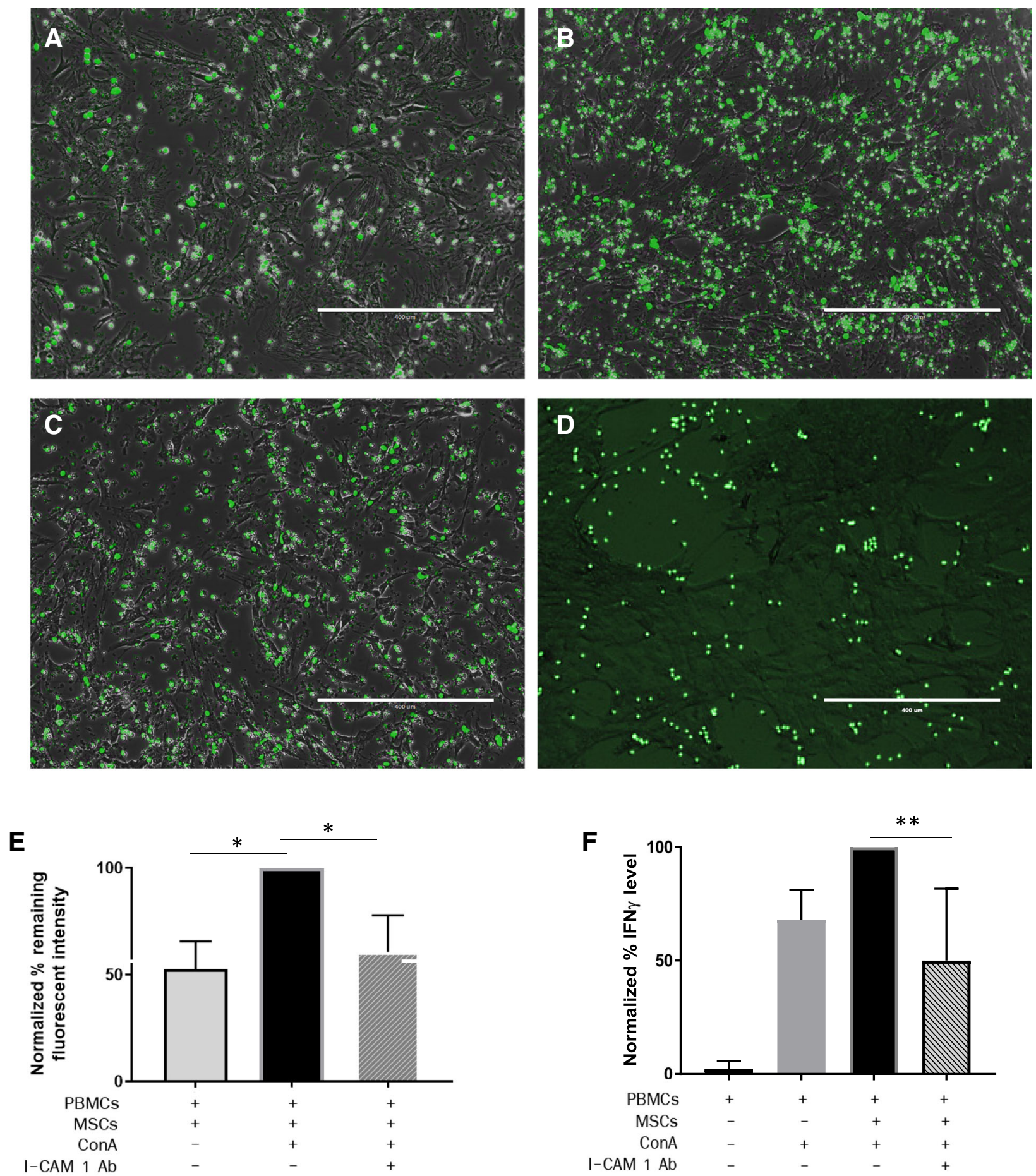

Fig. 5 I-CAM 1 ligand mediates the adhesion between feline ASCs and T lymphocytes. Fluorescent images of static adhesion assay demonstrating adherent lymphocytes to feline ASCs from a non-activated MLR, $\mathbf{b}$ stimulated MLR with ConA, $\mathbf{c}$ stimulated MLR with ConA and addition of ICAM-1 blocking antibodies, and $\mathbf{d}$ stimulated MLR with ConA and addition of ICAM-1/LFA-1 blocking antibodies. Scale bar $=400 \mu \mathrm{m}$. e Percentage of remaining fluorescence intensity from CMFDA-labeled PBMCs after removal of non-adherent cells from static adhesion assay with added condition of ICAM-1 blocking antibodies. Data is normalized to $100 \%$ on standard MLR condition for comparability. $\mathbf{f}$ Changes in IFN- $y$ concentration in the MLR after addition of ICAM-1 blocking antibodies. Data from 5 experiments, normalized to $100 \%$ on standard MLR condition for comparability. ${ }^{*} p<0.05$, ${ }^{* *} p<0.01$ 
disease, and feline asthma with varying degrees of success [3, 4, 34-36]. However, the exact mechanism(s) by which feline ASCs alter $\mathrm{T}$ cell responses remain vaguely understood. The objective of this study was to elucidate the underlying pathways utilized by feline ASCs to mitigate inflammatory conditions characterized by activated $\mathrm{T}$ cell proliferation.

MSCs can modulate $\mathrm{T}$ cell function, suppress $\mathrm{T}$ cell proliferation, and decrease $\mathrm{T}$ cell viability, but the mechanisms by which they accomplish these tasks are different between species and tissue sources. Based on our current study, we determined that feline ASCs inhibit T cell proliferation via cell cycle arrest in the G0-G1 phase, similar to murine BM-MSCs [37], equine BMand cord blood-derived MSCs [38], and canine ASCs (unpublished data). MSCs from other tissues sources, including equine ASCs and cord tissue-derived MSCs inhibit $\mathrm{T}$ cell proliferation through induction of apoptosis [38]. Human MSCs cause T cell apoptosis through a pathway mediated by IDO and IL-10 [39, 40]. Despite the species and tissue source variation, mechanisms underlying MSC inhibition of $\mathrm{T}$ cell responses are mediated by soluble factors and/or direct cell-to-cell interactions.

The interaction of cell surface receptors and their respective ligands on target cells are crucial for cell communication and modulation of cell functions [41]. ICAM-1 is an inducible cell adhesion glycoprotein expressed on the surface of a wide variety of cell types, including MSCs across different species [42]. ICAM-1 interactions with the $\beta 2$ integrin CD11a/CD18 (LFA-1) on the surface of lymphocytes are functionally important as costimulatory molecules for $\mathrm{T}$ cell activation [43]. In humans, ICAM-1 is constitutively expressed at a low level on the MSC surface but is significantly unregulated in the presence of pro-inflammatory cytokines, such as IFN- $\gamma[44,45]$. Here we demonstrate that feline MSCs express ICAM- 1 on their surface and that this molecule is similarly upregulated by activation. Further, our data demonstrate that this ligand plays a critical role in ASC-lymphocyte adhesion and signaling.

Although feline ASCs are capable of inhibiting lymphocyte proliferation in the absence of direct cell contact [8], the secretion profile of ASCs with and without direct cellcell contact is very different. Our current data demonstrate that ICAM-1/LFA-1 interaction is critical for cell-cell adhesion and plays an important role in the secretion of immunomodulatory mediators, from both T cells (IFN- $\gamma$ ) and MSCs $\left(\mathrm{PGE}_{2}\right)$, as blocking these ligands significantly reduced their concentration. Our findings mimic in vivo findings in a mouse model where blockade of ICAM-1 ligand also decreased IFN- $\gamma$ secretion and reduced pulmonary barrier damage in T cell-induced acute lung injury [46]. In mice, it was also found that the overexpression of ICAM-1 on MSCs can enhance the immunosuppressive effects of MSCs, including modulating $\mathrm{T}$ cell responses, dendritic cell maturation, and secretion of immunomodulatory soluble factors in vitro [47].

We also evaluated the ligand pairs CD137-CD137L and PD-1/PDL-1. CD137 (4-1BB), an inducible protein expressed on both CD4+ and CD8+ T cells, is functionally involved in signaling $\mathrm{T}$ cell proliferation [48]. CD137CD137L interaction has been implicated as one potential immunosuppressive mechanism used by human MSCs in the treatment of multiple sclerosis [49]. CD137-CD137L interaction has also been implicated for the paradoxical increase in IFN- $\gamma$ that supports CD8 T regulatory expansion [50]. Similarly, programmed death-1 (PD-1) and its ligand, PD-L1, is an important inhibitory pathway of $\mathrm{T}$ cell response and has been implicated as a crucial interaction used by human MSCs to inhibit T cell responses $[14,51]$. However, our data suggest that although CD137L and PDL-1 are expressed on activated feline ASCs, they are not the primary mediators of ASC T cell adhesion and do not mediate IFN- $\gamma$ secretion in vitro.

Upon activation, feline ASCs secrete several immunomodulatory mediators, including IDO, PGE ${ }_{2}$, IL-6, IL-8, and TGF- $\beta[8,29,52]$. However, the principal immunomodulatory mediators used by MSCs appear to vary by species. Human MSCs primarily utilize IDO whereas canine MSCs, both bone marrow-derived and adiposederived, utilize TGF- $\beta$ and $\mathrm{PGE}_{2}$ to suppress lymphocyte proliferation [53-55]. With feline ASCs, we found that blocking IDO, with 1-methyltryptophan, or adding a TGF- $\beta$ blocking antibody to the assay did not significantly alter $\mathrm{T}$ cell proliferation. Like dogs and horses, $\mathrm{PGE}_{2}$ is at least one soluble factor utilized by feline ASCs to block T cell proliferation as blocking $\mathrm{PGE}_{2}$ with indomethacin, a competitive inhibitor of $\mathrm{PGE}_{2}$, partially restored $\mathrm{T}$ cell proliferation $[12,53]$. However, the role of $\mathrm{PGE}_{2}$ was modest compared to similar experiments conducted with equine ASCs [38], implying that other soluble factors are also likely involved in feline ASC-T cell interaction. Despite a trend, blocking both $\mathrm{PGE}_{2}$ and IDO did not significantly restore $\mathrm{T}$ cell proliferation likely due to small sample size and the variability of $\mathrm{T}$ cell responses to mitogens from different cat donors.

Our findings are in agreement with data from others that used a different $\mathrm{PGE}_{2}$ inhibitor, NS-398, to reverse the immunosuppressive effects of feline ASCs [52]. Although nitric oxide (iNOS) is implicated in the mechanism of MSCmediated $\mathrm{T}$ cell suppression by both human and murine MSCs $[28,56]$, we found that feline ASCs do not produce a substantial amount of iNOS, either with or without activation. These findings correspond to a recent study where the level of iNOS RNA in feline ASCs was low or undetectable [29].

$\mathrm{PGE}_{2}$ is an eicosanoid lipid mediator which is produced by MSCs from most species, including human, murine, canine, equine, and feline [13, 57]. Although 
$\mathrm{PGE}_{2}$ may be pro-inflammatory in some contexts, it can also be immunosuppressive and is capable of decreasing IL-2 production from $\mathrm{T}$ cells and shifting CD4+ $\mathrm{T}$ cells from a predominantly cytotoxic Th1 response to a more balanced Th2/Th17-mediated response [58]. $\mathrm{PGE}_{2}$ also promotes the development of regulatory $\mathrm{T}$ cells and mediates their suppressive actions on effector $\mathrm{T}$ cells [59, 60]. These mechanisms may partially explain how feline ASCs are successfully used to treat FCGS, an immunemediated inflammatory disease.

MSCs generally require licensing with IFN- $\gamma$ to exert their immunosuppressive effects [61], our study showed that IFN- $\gamma$ is produced by both CD4+ and CD8+ T lymphocytes upon mitogen activation and the production of IFN- $\gamma$ from both $\mathrm{T}$ cell subsets is further enhanced by feline ASCs. These findings indicate that feline ASCs may be appropriate for therapeutic trials for both CD4+- and CD8+-mediated alloreactive diseases.

\section{Conclusion}

Feline ASCs utilize $\mathrm{PGE}_{2}$ and ICAM-1/LFA-1 ligand interaction to inhibit $\mathrm{T}$ cell proliferation by causing cell cycle arrest in the G0-G1 phase. While many questions remained to be addressed, these findings provide a deeper understanding of the underlying mechanisms involved in the immunosuppression by feline ASCs and will lead to more efficient implementations of ASCbased therapy for the modulation of immune-mediated inflammatory disease models.

\section{Additional file}

Additional file 1: Figure S1. Feline ASCs do not downregulate PD-1 expression on activated PBMCs. Flow analysis on PD-1 expression on activated T lymphocytes with and without co-incubation with feline ASCs. Representative image of flow cytometry analysis from 3 different MSC lines. (DOCX $185 \mathrm{~kb}$ )

\section{Abbreviations \\ ASC: Adipose-derived mesenchymal stem cell; BrdU: 5-Bromo-29- deoxyuridine; ConA: Concanavalin A; DPBS: Dulbecco's phosphate buffered saline; ELISA: Enzyme-linked immunosorbent assay; FBS: Fetal bovine serum IDO: Indoleamine 2,3 dioxygenase; IFN- $\gamma$ : Interferon gamma; MLR: Mixed leukocyte reaction; MSC: Mesenchymal stem cell; PBMC: Peripheral blood monocular cell; $\mathrm{PGE}_{2}$ : Prostaglandin E2; SPF: Specific pathogen free; TGF- $\beta$ : Transforming growth factor beta; TNF-a: Tumor necrosis factor alpha}

\section{Acknowledgements}

We would like to thank Dr. Emily Mills Ko and Dustin Leale for their technical support on IDO and iNOS measurement.

\section{Authors' contributions}

NT is responsible for the collection and assembly of data, data analysis and interpretation, and manuscript writing. SI is responsible for the collection and assembly of the data and review of the manuscript. NJW is responsible for the collection and assembly of the data and review of the manuscript. BA is responsible for the provision of the study material and review of the manuscript. DLB is responsible for the conception and design, data analysis, financial support, manuscript writing, and final approval of the manuscript. All authors read and approved the final manuscript.

\section{Funding}

This study was supported by the Winn Feline foundation and the Veterinary Institute for Regenerative Cures, School of Veterinary Medicine, University of California, Davis.

\section{Availability of data and materials}

All datasets used and/or analyzed during the current study are available from the corresponding author on reasonable request.

\section{Ethics approval and consent to participate}

Feline ASCs were obtained according to a protocol approved by the Institutional Animal Care and Use Committee, and the Clinical Trials Review Board, UCD (protocol number 18422). All owners of client-owned cats signed an informed consent form.

\section{Consent for publication}

Not applicable.

\section{Competing interests}

The authors declare that they have no competing interests.

\section{Author details}

${ }^{1}$ Department of Pathology, Microbiology and Immunology, Vet Med 3A, University of California, 1285 Veterinary Medicine Mall, Davis, CA 95616, USA. ${ }^{2}$ Department of Surgical and Radiological Sciences, University of California, Davis, CA 95616, USA. ${ }^{3}$ Veterinary Institute for Regenerative Cures, School of Veterinary Medicine, University of California, Davis, CA 95616, USA.

Received: 29 March 2019 Revised: 20 May 2019

Accepted: 7 June 2019 Published online: 25 June 2019

\section{References}

1. Horwitz EM, Le Blanc K, Dominici M, Mueller I, Slaper-Cortenbach I, Marini FC, et al. Clarification of the nomenclature for MSC: the International Society for Cellular Therapy position statement. Cytotherapy. 2005;7(5):393-5.

2. Nauta AJ, Fibbe WE. Immunomodulatory properties of mesenchymal stromal cells. Blood. 2007:110(10):3499-506.

3. Arzi B, Clark KC, Sundaram A, Spriet M, Verstraete FJM, Walker NJ, et al. Therapeutic efficacy of fresh, allogeneic mesenchymal stem cells for severe refractory feline chronic gingivostomatitis. Stem Cells Transl Med. 2017;6(8): $1710-22$.

4. Arzi B, Mills-Ko E, Verstraete FJ, Kol A, Walker NJ, Badgley MR, et al. Therapeutic efficacy of fresh, autologous mesenchymal stem cells for severe refractory gingivostomatitis in cats. Stem Cells Transl Med. 2016;5(1):75-86.

5. Le Blanc K, Tammik L, Sundberg B, Haynesworth SE, Ringden O. Mesenchymal stem cells inhibit and stimulate mixed lymphocyte cultures and mitogenic responses independently of the major histocompatibility complex. Scand J Immunol. 2003:57(1):11-20.

6. Krampera M, Cosmi L, Angeli R, Pasini A, Liotta F, Andreini A, et al. Role for interferon- $\gamma$ in the immunomodulatory activity of human bone marrow mesenchymal stem cells. Stem Cells. 2006;24(2):386-98.

7. Ghannam S, Bouffi C, Djouad F, Jorgensen C, Noël D. Immunosuppression by mesenchymal stem cells: mechanisms and clinical applications. Stem Cell Res Ther. 2010;1(1):2

8. Clark KC, Fierro FA, Ko EM, Walker NJ, Arzi B, Tepper CG, et al. Human and feline adipose-derived mesenchymal stem cells have comparable phenotype, immunomodulatory functions, and transcriptome. Stem Cell Res Ther. 2017;8(1):69.

9. Klyushnenkova E, Mosca JD, Zernetkina V, Majumdar MK, Beggs KJ, Simonetti DW, et al. T cell responses to allogeneic human mesenchymal stem cells: immunogenicity, tolerance, and suppression. J Biomed Sci. 2005;12(1):47-57.

10. Ciccocioppo R, Cangemi GC, Kruzliak P, Gallia A, Betti E, Badulli C, et al. Ex vivo immunosuppressive effects of mesenchymal stem cells on Crohn's disease mucosal T cells are largely dependent on indoleamine 2,3dioxygenase activity and cell-cell contact. Stem Cell Res Ther. 2015;6:137.

11. Ren G, Zhang L, Zhao X, Xu G, Zhang Y, Roberts Al, et al. Mesenchymal stem cell-mediated immunosuppression occurs via concerted action of chemokines and nitric oxide. Cell Stem Cell. 2008;2(2):141-50.

12. Carrade DD, Lame MW, Kent MS, Clark KC, Walker NJ, Borjesson DL. Comparative analysis of the immunomodulatory properties of equine adultderived mesenchymal stem cells. Cell Med. 2012;4(1):1-11. 
13. Kang JW, Kang KS, Koo HC, Park JR, Choi EW, Park YH. Soluble factorsmediated immunomodulatory effects of canine adipose tissue-derived mesenchymal stem cells. Stem Cells Dev. 2008;17(4):681-93.

14. Augello A, Tasso R, Negrini SM, Amateis A, Indiveri F, Cancedda R, et al. Bone marrow mesenchymal progenitor cells inhibit lymphocyte proliferation by activation of the programmed death 1 pathway. Eur $\rfloor$ Immunol. 2005;35(5):1482-90.

15. Ren G, Zhao X, Zhang L, Zhang J, L'Huillier A, Ling W, et al. Inflammatory cytokine-induced intercellular adhesion molecule-1 and vascular cell adhesion molecule-1 in mesenchymal stem cells are critical for immunosuppression. J Immunol. 2010;184(5):2321-8.

16. Lebedeva T, Dustin ML, Sykulev Y. ICAM-1 co-stimulates target cells to facilitate antigen presentation. Curr Opin Immunol. 2005;17(3):251-8.

17. Davies LC, Heldring N, Kadri N, Le Blanc K. Mesenchymal stromal cell secretion of programmed death-1 ligands regulates $T$ cell mediated immunosuppression. Stem Cells. 2017;35(3):766-76

18. Melero I, Murillo O, Dubrot J, Hervas-Stubbs S, Perez-Gracia JL. Multi-layered action mechanisms of CD137 (4-1BB)-targeted immunotherapies. Trends Pharmacol Sci. 2008;29(8):383-90.

19. Myers L, Lee SW, Rossi RJ, Lefrancois L, Kwon BS, Mittler RS, et al. Combined CD137 (4-1BB) and adjuvant therapy generates a developing pool of peptide-specific CD8 memory T cells. Int Immunol. 2006;18(2):325-33.

20. Seo SK, Choi JH, Kim YH, Kang WJ, Park HY, Suh JH, et al. 4-1BB-mediated immunotherapy of rheumatoid arthritis. Nat Med. 2004;10(10):1088-94.

21. Sun Y, Chen HM, Subudhi SK, Chen J, Koka R, Chen L, et al. Costimulatory molecule-targeted antibody therapy of a spontaneous autoimmune disease. Nat Med. 2002;8(12):1405-13.

22. Boaz A, Amir K, Brian M, WN J, WJ A, Kaitlin C, et al. Feline foamy virus adversely affects feline mesenchymal stem cell culture and expansion: implications for animal model development. Stem Cells Dev. 2015;24(7):814-23.

23. Miller MM, Petty CS, Tompkins MB, Fogle JE. CD4+CD25+ T regulatory cells activated during feline immunodeficiency virus infection convert T helper cells into functional suppressors through a membrane-bound TGF $\beta$ / GARPmediated mechanism. Virol J. 2014;11:7.

24. Villatoro AJ, Alcoholado C, Martín-Astorga MC, Fernández V, Cifuentes M, Becerra J. Comparative analysis and characterization of soluble factors and exosomes from cultured adipose tissue and bone marrow mesenchymal stem cells in canine species. Vet Immunol Immunopathol. 2019;208:6-15.

25. Gonzalez-Rey E, Gonzalez MA, Varela N, O'Valle F, Hernandez-Cortes P, Rico $L$, et al. Human adipose-derived mesenchymal stem cells reduce inflammatory and T cell responses and induce regulatory T cells in vitro in rheumatoid arthritis. Ann Rheum Dis. 2010;69(1):241-8.

26. Liu Y, Wang L, Kikuiri T, Akiyama K, Chen C, Xu X, et al. Mesenchymal stem cell-based tissue regeneration is governed by recipient $T$ lymphocytes via IFN- $\gamma$ and TNF-a. Nat Med. 2011;17:1594.

27. Luz-Crawford P, Kurte M, Bravo-Alegría J, Contreras R, Nova-Lamperti E, Tejedor G, et al. Mesenchymal stem cells generate a CD4+CD25+Foxp3+ regulatory $T$ cell population during the differentiation process of Th1 and Th17 cells. Stem Cell Res Ther. 2013;4(3):65.

28. Sato K, Ozaki K, Oh I, Meguro A, Hatanaka K, Nagai T, et al. Nitric oxide plays a critical role in suppression of T-cell proliferation by mesenchymal stem cells. Blood. 2007;109(1):228-34.

29. Parys M, Kruger JM, Yuzbasiyan-Gurkan V. Evaluation of immunomodulatory properties of feline mesenchymal stem cells. Stem Cells Dev. 2017;26(10): 776-85

30. Olyslaegers DAJ, Dedeurwaerder A, Desmarets LMB, Vermeulen BL, Dewerchin $\mathrm{HL}$, Naumynck HJ. Altered expression of adhesion molecules on peripheral blood leukocytes in feline infectious peritonitis. Vet Microbiol. 2013;166(3):438-49.

31. Achleitner A, Clark ME, Bienzle D. T-regulatory cells infected with feline immunodeficiency virus up-regulate programmed death-1 (PD-1). Vet Immunol Immunopathol. 2011;143(3):307-13.

32. Hoffman AM, Dow SW. Concise review: stem cell trials using companion animal disease models. Stem Cells. 2016;34(7):1709-29.

33. Kol A, Arzi B, Athanasiou KA, Farmer DL, Nolta JA, Rebhun RB, et al. Companion animals: translational scientist's new best friends. Sci Transl Med. 2015:7(308):308ps21.

34. Quimby JM, Webb TL, Randall E, Marolf A, Valdes-Martinez A, Dow SW. Assessment of intravenous adipose-derived allogeneic mesenchymal stem cells for the treatment of feline chronic kidney disease: a randomized, placebo-controlled clinical trial in eight cats. J Feline Med Surg. 2016;18(2): 165-71.
35. Trzil JE, Masseau I, Webb TL, Chang C-H, Dodam JR, Cohn LA, et al. Longterm evaluation of mesenchymal stem cell therapy in a feline model of chronic allergic asthma. Clin Exp Allergy. 2014;44(12):1546-57.

36. Webb TL, Webb CB. Stem cell therapy in cats with chronic enteropathy: a proof-of-concept study. J Feline Med Surg. 2015;17(10):901-8.

37. Glennie S, Soeiro I, Dyson PJ, Lam EW, Dazzi F. Bone marrow mesenchymal stem cells induce division arrest anergy of activated T cells. Blood. 2005;105(7):2821-7.

38. Carrade Holt DD, Wood JA, Granick JL, Walker NJ, Clark KC, Borjesson DL. Equine mesenchymal stem cells inhibit T cell proliferation through different mechanisms depending on tissue source. Stem Cells Dev. 2014;23(11):1258-65.

39. Plumas J, Chaperot L, Richard MJ, Molens JP, Bensa JC, Favrot MC. Mesenchymal stem cells induce apoptosis of activated T cells. Leukemia. 2005;19:1597.

40. Yang S-H, Park M-J, Yoon I-H, Kim S-Y, Hong S-H, Shin J-Y, et al. Soluble mediators from mesenchymal stem cells suppress $T$ cell proliferation by inducing IL-10. Exp Mol Med. 2009;41:315.

41. Schwartz MA, Schaller MD, Ginsberg MH. Integrins: emerging paradigms of signal transduction. Annu Rev Cell Dev Biol. 1995;11:549-99.

42. Roebuck KA, Finnegan A. Regulation of intercellular adhesion molecule-1 (CD54) gene expression. J Leukoc Biol. 1999;66(6):876-88.

43. Dubey $C$, Croft M, Swain SL. Costimulatory requirements of naive CD4+ $T$ cells. ICAM-1 or B7-1 can costimulate naive CD4 T cell activation but both are required for optimum response. J Immunol. 1995;155(1):45-57.

44. Jahnke A, Johnson JP. Intercellular adhesion molecule 1 (ICAM-1) is synergistically activated by TNF- $a$ and IFN- $\gamma$ responsive sites. Immunobiology. 1995;193(2):305-14.

45. Majumdar MK, Keane-Moore M, Buyaner D, Hardy WB, Moorman MA, McIntosh $\mathrm{KR}$, et al. Characterization and functionality of cell surface molecules on human mesenchymal stem cells. J Biomed Sci. 2003;10(2):228-41.

46. Svedova J, Ménoret A, Mittal P, Ryan JM, Buturla JA, Vella AT. Therapeutic blockade of CD54 attenuates pulmonary barrier damage in T cell-induced acute lung injury. Am J Physiol Lung Cell Mol Physiol. 2017;313(1):L177-L91.

47. Tang B, Li X, Liu Y, Chen X, Li X, Chu Y, et al. The therapeutic effect of ICAM-1-overexpressing mesenchymal stem cells on acute graft-versus-host disease. Cell Physiol Biochem. 2018;46(6):2624-35.

48. Pollok KE, Kim YJ, Zhou Z, Hurtado J, Kim KK, Pickard RT, et al. Inducible T cell antigen 4-1BB. Analysis of expression and function. J Immunol. 1993; 150(3):771-81.

49. Christopeit M, Schendel M, Föll J, Müller LP, Keysser G, Behre G. Marked improvement of severe progressive systemic sclerosis after transplantation of mesenchymal stem cells from an allogeneic haploidentical-related donor mediated by ligation of CD137L. Leukemia. 2007;22:1062.

50. Kang SW, Lee SC, Park SH, Kim J, Kim HH, Lee HW, et al. Anti-CD137 suppresses tumor growth by blocking reverse signaling by CD137 ligand. Cancer Res. 2017;77(21):5989-6000.

51. Gao W, Demirci G, Strom TB, Li XC. Stimulating PD-1-negative signals concurrent with blocking CD154 co-stimulation induces long-term islet allograft survival. Transplantation. 2003;76(6):994-9.

52. Chae HK, Song WJ, Ahn JO, Li Q, Lee BY, Kweon K, et al. Immunomodulatory effects of soluble factors secreted by feline adipose tissue-derived mesenchymal stem cells. Vet Immunol Immunopathol. 2017;191:22-9.

53. Chow L, Johnson V, Coy J, Regan D, Dow S. Mechanisms of immune suppression utilized by canine adipose and bone marrow-derived mesenchymal stem cells. Stem Cells Dev. 2017;26(5):374-89.

54. Kol A, Foutouhi S, Walker NJ, Kong NT, Weimer BC, Borjesson DL. Gastrointestinal microbes interact with canine adipose-derived mesenchymal stem cells in vitro and enhance immunomodulatory functions. Stem Cells Dev. 2014;23(16):1831-43.

55. Meisel R, Brockers S, Heseler K, Degistirici O, Bulle H, Woite C, et al. Human but not murine multipotent mesenchymal stromal cells exhibit broadspectrum antimicrobial effector function mediated by indoleamine 2,3dioxygenase. Leukemia. 2011;25(4):648-54.

56. Ren G, Su J, Zhang L, Zhao X, Ling W, L'Huillie A, et al. Species variation in the mechanisms of mesenchymal stem cell-mediated immunosuppression. Stem Cells. 2009;27(8):1954-62

57. Ma S, Xie N, Li W, Yuan B, Shi Y, Wang Y. Immunobiology of mesenchymal stem cells. Cell Death Differ. 2013;21:216.

58. Kalinski P. Regulation of immune responses by prostaglandin E2. J Immunol. 2012;188(1):21-8

59. Baratelli F, Lin Y, Zhu L, Yang SC, Heuze-Vourc'h N, Zeng G, et al. Prostaglandin E2 induces FOXP3 gene expression and T regulatory cell function in human CD4+ T cells. J Immunol. 2005;175(3):1483-90. 
60. Mahic M, Yaqub S, Johansson CC, Tasken K, Aandahl EM. FOXP3+CD4+ CD25+ adaptive regulatory T cells express cyclooxygenase-2 and suppress effector T cells by a prostaglandin E2-dependent mechanism. J Immunol. 2006;177(1):246-54.

61. Ryan JM, Barry F, Murphy JM, Mahon BP. Interferon- $y$ does not break, but promotes the immunosuppressive capacity of adult human mesenchymal stem cells. Clin Exp Immunol. 2007;149(2):353-63.

\section{Publisher's Note}

Springer Nature remains neutral with regard to jurisdictional claims in published maps and institutional affiliations.

Ready to submit your research? Choose BMC and benefit from:

- fast, convenient online submission

- thorough peer review by experienced researchers in your field

- rapid publication on acceptance

- support for research data, including large and complex data types

- gold Open Access which fosters wider collaboration and increased citations

- maximum visibility for your research: over $100 \mathrm{M}$ website views per year

At $\mathrm{BMC}$, research is always in progress.

Learn more biomedcentral.com/submissions 